\title{
COMO O PROTECIONISMO DA JUSTIÇA TRABALHISTA BRASILEIRAIMPEDE O CRESCIMENTO DA EMPRESA
}

\author{
Bruna Rangel Barbosa ${ }^{1}$ \\ Clélio Marcondes Filho²
}

Resumo: O presente estudo tem o escopo de analisar como o protecionismo judiciário em relação ao empregado vem sendo nocivo a este, enquanto atrasa o desenvolvimento econômico da empresa e assim, do país. A metodologia utilizada baseia-se em artigos, súmulas e aspectos jurídico sociais. Objetivou-se por demonstrar como a justiça interfere o fluxo das relações trabalhistas com extremo protecionismo ao trabalhador. Como resultado se obteve que, por com conta da crise econômica atual brasileira, cominada ao protecionismo jurídico trabalhista, gerou-se intenso aumento do desemprego e fechamento de empresas. Conclui-se que, pelo quadro nacional, é necessário que haja uma flexibilização das leis trabalhistas a fim de insurgir a economia brasileira e melhora nas relações de trabalho, tornando estas mais adequadas e prolongadas.

Palavras-chave: Reforma Trabalhista; CLT, Flexibilização; Crise.

\footnotetext{
${ }^{1}$ Direito/Universidade do Vale do Paraíba, Brasil. E-mail: bru_rangel_mcr@hotmail.com.

2 Direito/Universidade do Vale do Paraíba, Brasil. E-mail: cmf@cleliomarcondes.adv.br.
} 